\title{
A Wideband Microstrip Rectangular Patch Antenna for Cognitive Radio Applications
}

\author{
Mohamed Khamis El Sayed \\ Faculty of Engineering, Cairo University, Giza, \\ Egypt
}

\begin{abstract}
A wideband Microstrip patch antenna consists of metallic patch and ground between which is a dielectric medium called the substrate. Microstrip patch antennas are used for communication purposes especially in Cognitive Radio applications. In this paper a simple Microstrip patch antenna is designed Using CST Microwave Studio for a Range from $1.1 \mathrm{GHz}$ to $3.1 \mathrm{GHz}$
\end{abstract}

\section{General Terms}

Wireless application, Cognitive Radio application

\section{Keywords}

Wideband, VSWR, Radiation pattern, Beamwidth, directivity, gain

\section{INTRODUCTION}

Microsrtip antennas are used for number of wireless applications such as WLAN [1][2], Wi-Fi[3], Bluetooth [4] and many other applications. A simple microstrip patch antenna consists of a conducting patch and ground plane between them is a dielectric medium called the substrate having a particular value of dielectric constant. The dimensions of a patch are smaller as compared to the substrate and ground. Dimensions of a microstrip patch antenna depend on the resonant frequency and value of the dielectric constant figure 1 .

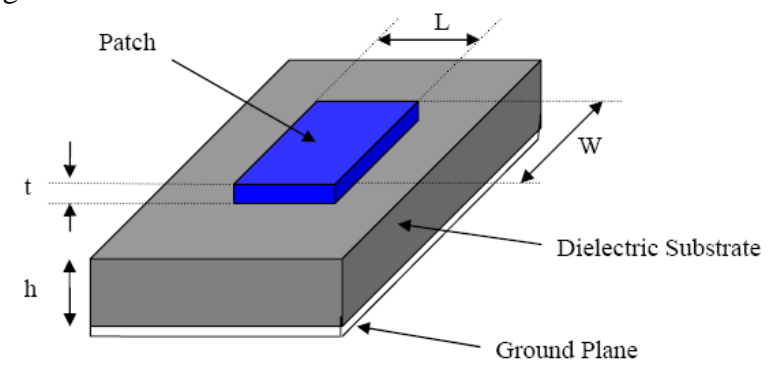

Figure 1 Structure of Micro Strip Antenna

\section{DESIGN PARAMETERS}

For designing of a microstrip patch antenna, we have to select the resonant frequency and a dielectric medium for which antenna is to be designed. The parameters to be calculated are as under. Width (W): The width of the patch is calculated using the following equation [5][3][6].

\author{
Amin Mohamed Nasser, PhD \\ Faculty of Engineering, Cairo University, Giza, \\ Egypt
}

$$
W=\frac{C_{0}}{2 f_{r}} \sqrt{\frac{2}{\varepsilon_{r}+1}}
$$

Where,

$$
\begin{aligned}
& \mathrm{W}=\text { Width of the patch } \\
& C_{\mathrm{C}}=\text { Speed of light } \\
& \varepsilon_{r} \text { = value of the dielectric substrate }
\end{aligned}
$$

Effective refractive index:

The effective refractive index value of a patch is an important parameter in the designing procedure of a microstrip patch antenna. The radiations traveling from the patch towards the ground pass through air and some through the substrate (called as fringing). Bath the air and the substrates have different dielectric values, therefore in order to account this we find the value of effective dielectric constant. The value of the effective dielectric constant $\left(\varepsilon_{\text {reff }}\right)$ is calculated using the following equation [5][3][6]: possible.

$$
\varepsilon_{\text {reff }}=\frac{\varepsilon_{r}+1}{2}+\frac{\varepsilon_{r}-1}{2}\left[1+12 \frac{h}{W}\right]^{-1 / 2}, W / h>1
$$

Length:

Due to fringing, electrically the size of the antenna is increased by an amount of $(\Delta \mathrm{L})$. Therefore, the actual increase in length $(\Delta \mathrm{L})$ of the patch is to be calculated using the following equation

$[5][3][6]:$

$$
\frac{\Delta L}{h}=0.412 \frac{\left(\varepsilon_{\text {eeff }}+0.3\right)\left(\frac{W}{h}+0.264\right)}{\left(\varepsilon_{\text {eeff }}-0.258\right)\left(\frac{W}{h}+0.8\right)}
$$

Where ' $h$ ' $=$ height of the substrate

The length (L) of the patch is now to be calculated using the below mentioned equation [5][3][6]:

$$
L=\frac{C_{0}}{2 f_{r} \sqrt{\varepsilon_{r e f f}}}-2 \Delta L
$$

Length ( $\mathrm{Lg}$ ) and widtg (Wg) of ground plane: Now the dimensions of a patch are known. The length and width of a 
substrate is equal to that of the ground plane. The length of a ground plane $(\mathrm{Lg})$ and the width of a ground plane $(\mathrm{Wg})$ are

Calculated using the following Equation [7]:

$$
\begin{aligned}
& L_{g}=6 h+L \\
& W_{g}=6 h+W
\end{aligned}
$$

For feeding the microstrip patch antenna, there are different methods for example, feed line method, coaxial probe feeding method etc. But mostly coaxial probe method is used.

\section{Proposed antenna design}

Using the equations mentioned above, a Rectangular microstrip patch antenna is designed to cover the range from 1.1 GHZ to $3.1 \mathrm{GHZ}$. The length width (W) and length (L) of the patch is found to be $40 \mathrm{~mm}$ and $31 \mathrm{~mm}$ respectively. The height of the substrate is $3 \mathrm{~mm}$. for ground plane, the length $(\mathrm{Lg})$ and width $(\mathrm{Wg})$ of the ground plane is calculated to be $80 \mathrm{~mm}$ and $60 \mathrm{~mm}$ respectively. The simulation is carried out in CST Microwave Studio software as shown in below figure 2 and figure 3.

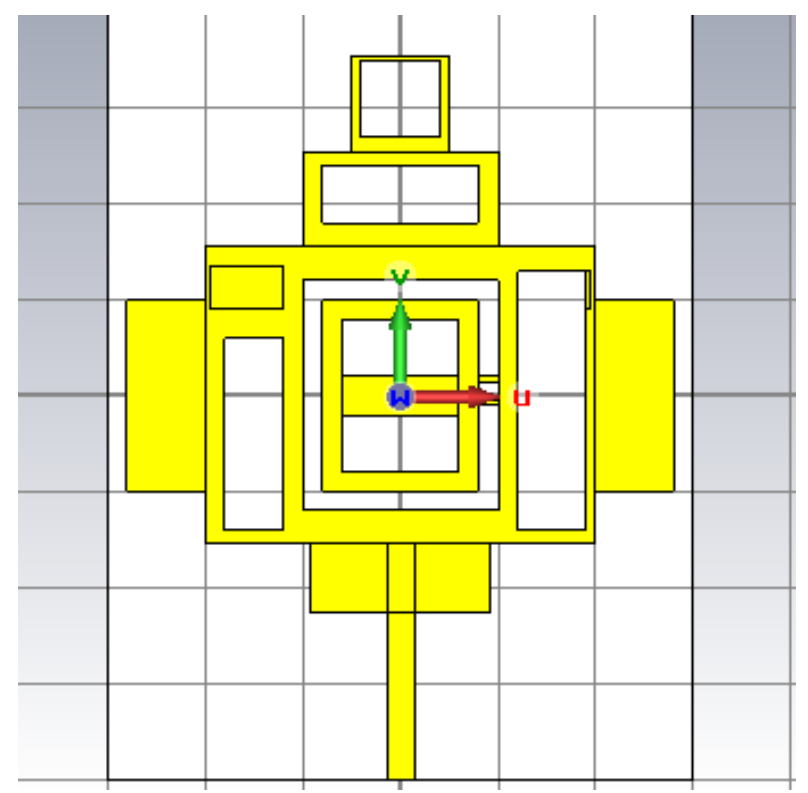

Figure 2 the Antenna Patch

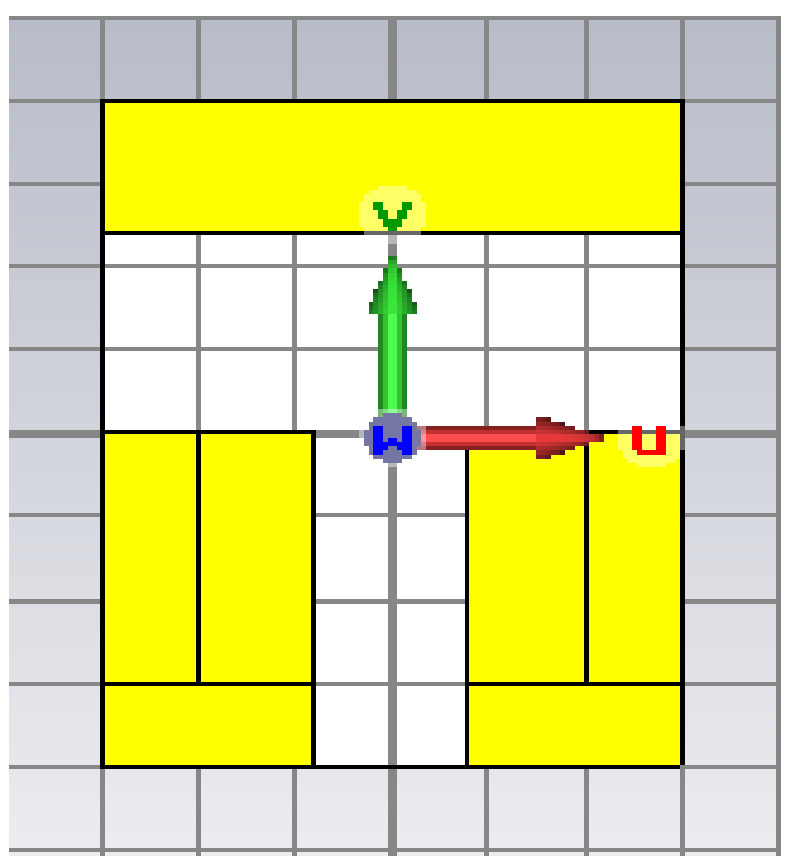

Figure 3 the Antenna Ground Plane

\section{SIMULATION \& RESULT}

The simulated results show that the standing wave ratio (VSWR) is less than 2 figure 4. the Return Loss (S11) is less than $-10 \mathrm{~dB}$ and the best value of $\mathrm{S} 11=-31 \mathrm{~dB}$ at $1.45 \mathrm{GHz}$ figure 5 . at frequency $2 \mathrm{GHz}$, the max power is $3.93 \mathrm{db}$ at $163 \mathrm{deg}$. and the half power Beamwidth $=73.3 \mathrm{deg}$. figure 6 . The max antenna gain is $5.88 \mathrm{db}$ figure 7 . 


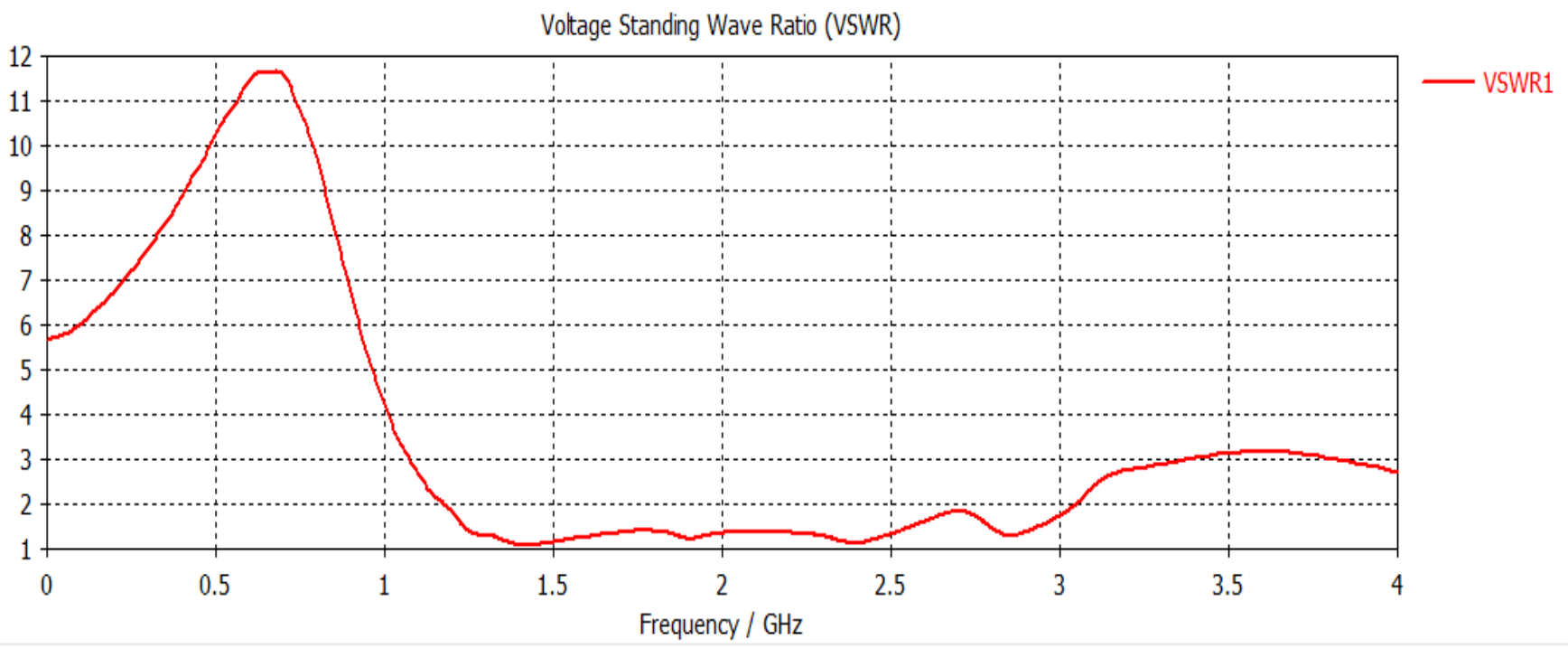

Figure 4 Voltage standing wave Ratio (VSWR) of the proposed antenna

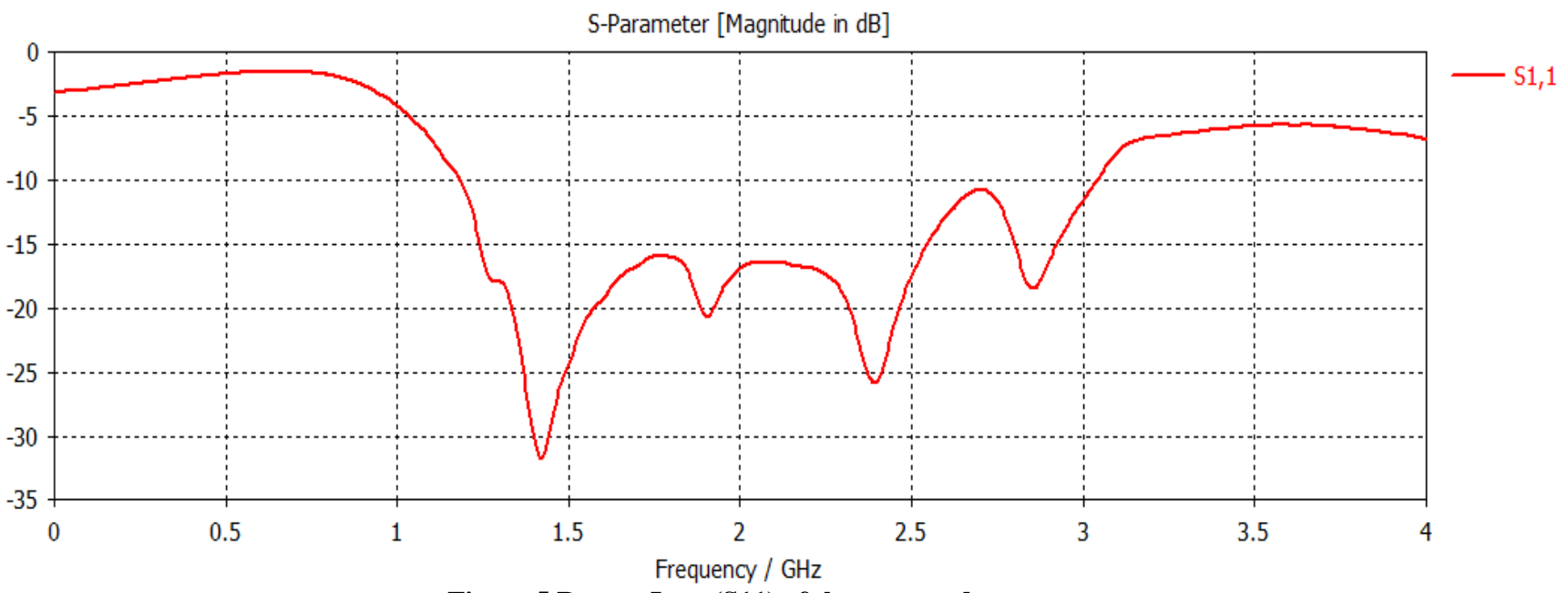

Figure 5 Return Loss (S11) of the proposed antenna

Farfield Directivity Abs (Phi=90)

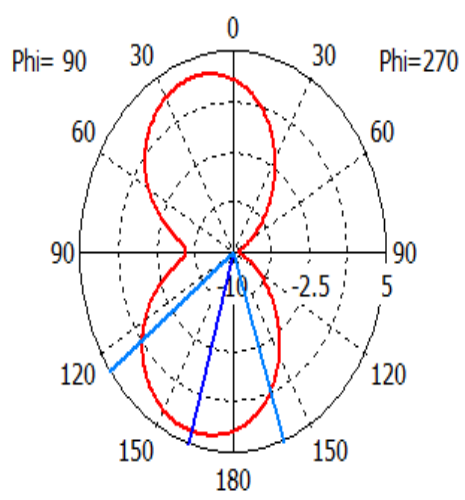

Theta / Degree vs. dBi
Frequency $=2$

Main lobe magnitude $=3.93 \mathrm{~dB}$ Main lobe direction $=163.0 \mathrm{deg}$. Angular width $(3 \mathrm{~dB})=73.3 \mathrm{deg}$.

Figure. 6: Polar plot of far field pattern of proposed antenna at frequency $2 \mathrm{GHz}$ 


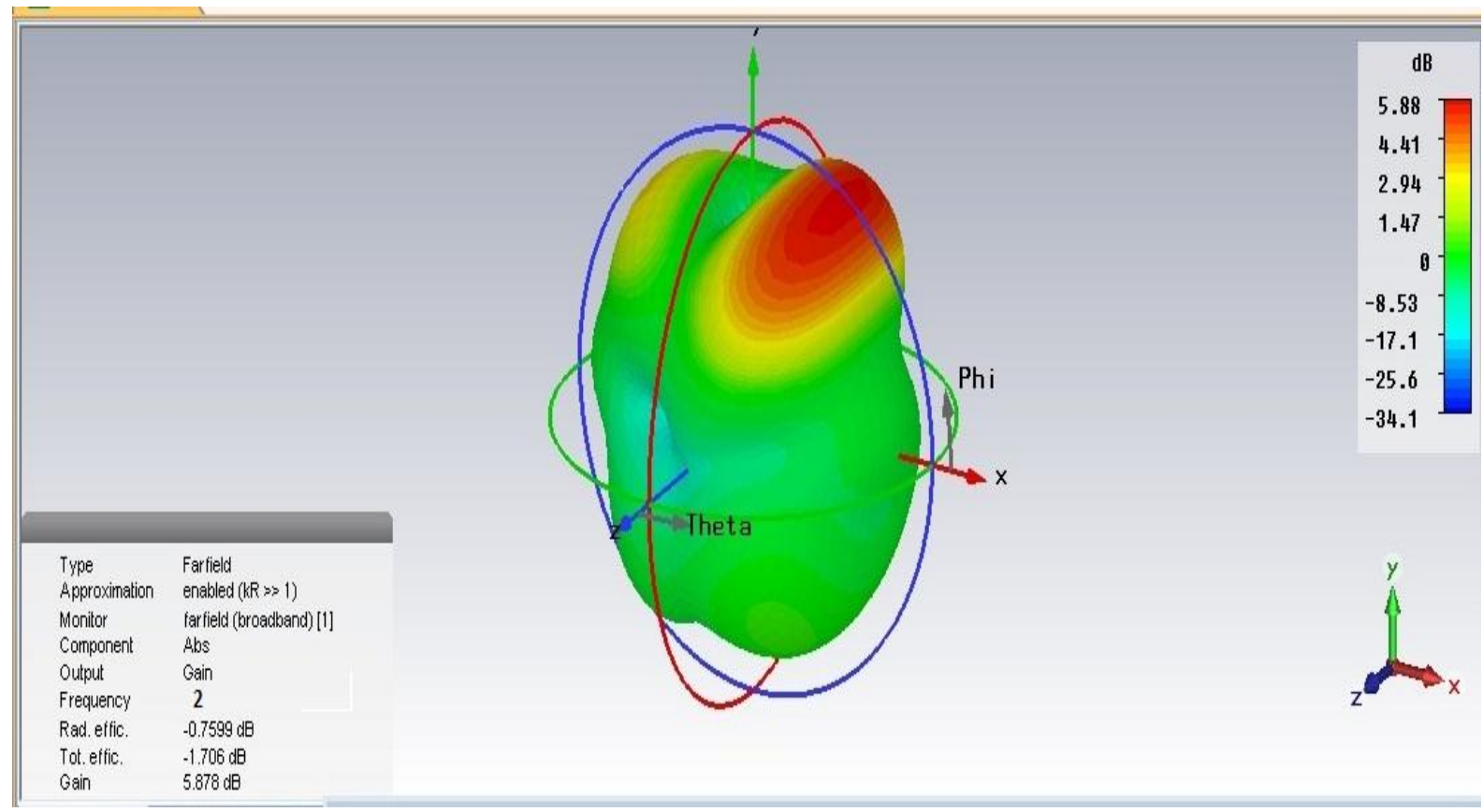

Figure. 7: 3D plot of far field pattern of proposed antenna at frequency $2 \mathrm{GHz}$

\section{CONCLUSION}

In this paper a microstrip rectangular patch antenna is successfully designed at the range from $1.1 \mathrm{GHz}$. To $3.1 \mathrm{GHz}$ the antenna simulation shows a gain is $5.88 \mathrm{db}$, The VSWR of the antenna is less than 2 and the $\mathrm{S} 11$ is less than $-10 \mathrm{db}$

\section{REFERENCES}

[1] Chandan Kumar Ghosh and Susanta Kumar Parui "Design, Analysis and Optimization of A Slotted Microstrip Patch Antenna Array at Frequency 5.25 GHz for WLAN-SDMA System" International Journal on Electrical Engineering and Informatics - Volume 2, Number 2, 2010

[2] Jaswinder Kaur, Rajesh Khanna "Co-axial Fed Rectangular Microstrip Patch Antenna for $5.2 \mathrm{GHz}$ WLAN Application" Universal Journal of Electrical and Electronic Engineering 1(3):94-98, 2013 DOI: 10.13189/ujeee.2013.010306 http://www.hrpub.org

[3] J. G. Vera-Dimas, M. Tecpoyotl-Torres, P. VargasChable, J. A. Damián-Morales J. Escobedo-Alatorre and S. Koshevaya "Individual Patch Antenna and Antenna Patch Array for Wi-Fi Communication" Center for Research of Engineering and Applied Sciences (CIICAp), Autonomous University of Morelos State (UAEM), 62209, Av. Universidad No.1001, Col Chamilpa, Cuernavaca, Morelos, México.
[4] AlakMajumder "Design of an H-shaped Microstrip Patch Antenna for Bluetooth Applications" International Journal of Innovation and Applied Studies ISSN 20289324 Vol. 3 No. 4 Aug. 2013, pp. 987-994 (C) 2013 Innovative Space of Scientific Research Journals http://www.issr-journals.org/ijias/

[5] Ramna, Amandeep Singh Sappal "DESIGN of RECTANGULAR MICROSTRIP PATCH ANTENNA USING PARTICLE SWARM OPTIMIZATION "International Journal of Advanced Research in Computer and Communication EngineeringVol. 2, Issue 7, July 2013

[6] Md. MarufAhamed, Kishore Bhowmik, Abdulla Al Suman "Analysis And Design of Rectangular Microstrip Patch Antenna On Different Resonant Frequencies For Pervasive Wireless Communication" INTERNATIONAL JOURNAL OF SCIENTIFIC \& TECHNOLOGY RESEARCH VOLUME 1, ISSUE 5, JUNE 2012

[7] Sukhbir Kumar, Hitender Gupta"Design and Study of Compact and Wideband Microstrip U-Slot Patch Antenna for Wi-Max Application" IOSR Journal of Electronics and Communication Engineering (IOSRJECE) e-ISSN: 2278-2834,p- ISSN: 2278-8735. Volume 5, Issue 2 (Mar. - Apr. 2013), PP 45-48 www.iosrjournals.org 